Biological and Applied Sciences

Vol.59: e16160245, January-December 2016 http://dx.doi.org/10.1590/1678-4324-2016160245 ISSN 1678-4324 Online Edition

\title{
Applications of Plackett-Burman and Central Composite Design for the Optimization of Novel Brevundimonas diminuta KT277492 Chitinase Production, Investigation of its Antifungal Activity
}

\author{
Warda, E. Ashour'; Abeer, A. Abd El Aty ${ }^{1 *}$; Eman R. Hamed ${ }^{1}$; Mahmoud, A. Swelim²; \\ Ahmed I. El-Diwany ${ }^{1}$. \\ ${ }^{I}$ Chemistry of Natural and Microbial Products Department, Pharmaceutical and Drug Industries Research \\ Division, National Research Center, Dokki-12311, Giza, Egypt. ${ }^{2}$ Botany department, Faculty of science, Banha \\ University, Egypt.
}

\begin{abstract}
Biological control strategy which can damage chitin, a vital component of pathogenic fungi and arthropods promises a safe solution for many fungal problems. And it's more favorable than chemicals which increase health risks and environmental problems. Thus, the chitinase producers appear potential candidates of biological control of pathogenic fungi. Brevundimonus diminuta KT277492 is a new isolate that has been isolated recently from Egyptian soil. Significant factors that affecting the chitinase enzyme production were studied and optimized using Plackett-Burman and Response Surface Methodology (RSM). As a result, maximum production of chitinase enzyme was $832.87 \mathrm{IUL}^{-1}$, this result presented about 8.767-fold increase in the enzyme production. In the last phase of the study, partially purified chitinase enzyme obtained from B. diminuta KT277492 was tested against two pathogenic fungi and the results showed good inhibitory activity against A. alternata and F. solani with IZD of $31 \pm 0.25$ and $25 \pm 0.91 \mathrm{~mm}$ respectively. Finally, obtained results indicated the value of optimization process and the optimized chitinase enzyme could be an excellent choice in application of food and biotechnology as a biofungicide. This reflects the necessity of studying the characteristics and kinetics of the enzyme in the forthcoming study.
\end{abstract}

Key words: chitinase, Brevundimonas diminuta KT277492, optimization, Plackett-Burman, central composite design, antifungal.

*Authors for correspondence: aabass44@yahoo.com 


\section{INTRODUCTION}

According to ${ }^{1}$ Chitin is the second most abundant insoluble biodegradable polymer, which exists naturally in the biosphere as a structural polysaccharide of 1,4-N-acetyl-D-glucosamine. It is highly distributed in nature, as a constituent of insect exoskeleton, shells of crustaceans, fungal cell walls and algae components ${ }^{2}$. Chitinases enzymes (E.C.3.2.1.14) capable of hydrolyzing chitin to its oligo and monomeric components. There are several sources for chitinases as, microorganisms ${ }^{2}$, higher plants ${ }^{3}$, even lower animals and birds ${ }^{4}$.

Bacterial chitinases are believed to be important in the hydrolysis process of chitin for utilization as an energy and carbon sources, therefore, they have been implicated in protection against parasites in fungi, protozoa, invertebrates and especially in breakdown of chitin in the cell wall of fungal pathogens. ${ }^{5,6}$. One of such bacteria are Brevundimonus sp. that able to produce the lytic enzymes such as chitinase and has tremendous impact for an industrial scale production ${ }^{7}$. Recently, Ashour et al ${ }^{8}$ locally isolated the rhizobacterial strain Brevundimonus diminuta KT277492 from rhizosphere of Trigonella foenum- graecum $L$ in Egypt. The qualitative colloidal chitin agar plate test suggested its ability for first time to produce chitinase enzyme better than other isolates.

Chitinases are gaining much more attention worldwide because they have wide range of applications in the food, cosmetic industries, medical and fertilizer production areas 9, 10. Also important in the biocontrol of fungal diseases in plants ${ }^{11}$ and as biobestsides ${ }^{12}$.

In microorganisms, chitinase production is controlled by a receptor-inducer system; therefore, the composition of the culture medium can affect chitinase production ${ }^{13}$. The conventional method for medium optimization involves changing one parameter at a time while keeping all others constant may be very expensive and time consuming. Furthermore, it is not effective to determine the combined effect of different factors. A number of statistical experimental designs have been used to overcome these problems ${ }^{13,14}$. One of these methods are full factorial designs which provide more complete information.

The Plackett-Burman design ${ }^{15}$, as a two level fractional factorial design, is especially useful in screening studies by estimating the main effects of variables. The variables screened by PlackettBurman design can be optimized by using statistical and mathematical optimization tools such as response surface methodology (RSM) ${ }^{16}$. Recent studies have indicated the use of RSM for analyzing effects of different factors on enzyme activity ${ }^{17}$ and optimization of enzyme production 18.

The present study directed towards the improvement and optimization of the valuable newly isolated Brevundimonus diminuta KT277492 chitinase enzyme. Depending on the novel statistical designs and estimation of its antifungal activity important for biological control strategies of pathogenic fungi.

\section{MATERIALS AND METHODS}

\section{Chemicals}

Chitin was purchased from (Sigma-Aldrich-MOUSA). Other reagents were of analytical grade.

\section{Microorganism and maintenance}

The rhizobacterial strain Brevundimonus diminuta KT277492 used in this study, was locally isolated from rhizosphere of Trigonella foenum- graecum $L$. collected from the green house of Ministry of Agriculture, Giza, Egypt. ${ }^{8}$. The stock culture was maintained on nutrient agar slants at $4{ }^{\circ} \mathrm{C}$ and periodically subcultured in the National Research Center, Chemistry of Natural and Microbial Products Dept. ${ }^{1}$.

\section{Culture conditions for chitinase enzymes production \\ Preparation of seed culture}

The seed culture was prepared by inoculating single colony in a plate containing the medium composed of $\left(\mathrm{gl}^{-1}\right)$ glucose 2.0 , peptone 4.0,

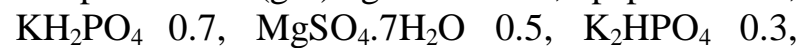
$\mathrm{FeSO}_{4} \cdot 7 \mathrm{H}_{2} \mathrm{O}, 0.02$ and agar 20.0. The plates incubated for $48 \mathrm{~h}$ at $30^{\circ} \mathrm{C}$, after that a loop full of the colony transferred to $50 \mathrm{~mL}$ seed liquid medium, initial pH 7 in $250 \mathrm{~mL}$ Erlenmeyer flasks and incubated under shaking (200 rpm) for $48 \mathrm{~h}$ at $30^{\circ} \mathrm{C}$.

\section{Chitinase production medium}

Nutrient broth medium (NB) used as basal medium for chitinase production. The medium contained the following components $\left(\mathrm{gl}^{-1}\right)$ : yeast extract 1.5, $\mathrm{NaCl} 5.0$, beef extract 1.5, 
supplemented with $0.1 \%$ colloidal chitin ${ }^{19} .250$ $\mathrm{mL}$ Erlenmeyer flasks containing $50 \mathrm{~mL}$ of NB medium autoclaved at $121^{\circ} \mathrm{C}$ for $20 \mathrm{~min}$. After cooling, each flask was inoculated with $1 \mathrm{~mL}$ containing $\left(1 \times 10^{8}\right.$ spores $\left.^{-\mathrm{ml}}\right)$ of the fresh seed culture and incubated under the same conditions mentioned above. All the experiments were carried out in duplicate and the average values are reported as mean \pm SD calculated using MS Excel.

\section{Effect of incubation period on the chitinase production}

The time courses of the chitinase production by B.diminuta KT277492, using the basal production medium were monitored for $168 \mathrm{~h}$ after $24 \mathrm{~h}$ intervals, fermentation broth was centrifuged and chitinase activity was determined ${ }^{1}$.

\section{Chitinase activity assay}

According to ${ }^{20}$ chitinase activity was determined by a dinitrosalicylic acid (DNS) method ${ }^{21}$ with some modification. This method works on the concentration of $\mathrm{N}$-acetyl glucosamine (NAG), which is released as a result of enzymatic action ${ }^{22}$. The $2 \mathrm{~mL}$ reaction mixture contained $0.5 \mathrm{~mL}$ of $0.5 \%$ colloidal chitin in acetate buffer ( $\mathrm{pH} 5.5$ ), $0.5 \mathrm{~mL}$ crude enzyme extract and $1 \mathrm{~mL}$ distilled water. The well vortexed mixture was incubated in a water bath shaker at $40^{\circ} \mathrm{C}$ for $2 \mathrm{~h}$. The reaction was arrested by the addition of $3 \mathrm{~mL}$ DNS reagent followed by heating at $100^{\circ} \mathrm{C}$ for $10 \mathrm{~min}$ with $40 \%$ Rochelle's salt solution. The colored solution was centrifuged at 10,000 rotations per minute for 5 min and the absorption of the appropriately diluted test sample was measured at $530 \mathrm{~nm}$ using UV spectrophotometer (UV-160 A, Shimadzu, Japan) along with substrate and enzyme blanks. Colloidal chitin was prepared by the modified method of ${ }^{23}$. One unit (IU) of the chitinase activity is defined as the amount of enzyme that is required to release $1 \mu \mathrm{mol}$ of $\mathrm{N}$-acetyl-d-glucosamine per minute from $0.5 \%$ of colloidal chitin solution under assay conditions.

\section{Statistical optimization of B.diminuta KT277492 chitinase enzyme \\ Screening of critical media components using Plackett-Burman design}

According to Shehata and Abd El Aty ${ }^{24}$ PlackettBurman factorial design was used in our study to select significant medium components affecting the production of chitinase. Eleven medial components (chitin, glucose, starch, fructose, peptone, yeast extract, urea, potassium dihydrogen phosphate, dipotassium hydrogen phosphate, magnesium sulphate, sodium sulfate) were studied. Each variable was represented at 2-levels, upper ('high, +') and lower ('low, -') levels of the range covered by each variable and the response Table (1). Experimental responses were analyzed by first order model by the following equation $\mathrm{Y}=\beta_{0}+\sum$ $\beta_{i} x_{i}$, where $\mathrm{Y}$ is the response for chitinase production, $\mathrm{B}_{o}$ is the model intercept and $\beta_{i}$ is the linear coefficient, and $x_{i}$ is the level of the independent variable. According to the Stat-Ease analysis, a first-order model could be obtained from the regression results of fractional factorial experiment. This model describes the interaction among factors and it is used to screen and evaluate important factors that influence the response. The main effect of each variable was determined according to the following equation: $E_{x i}=\left(\Sigma M_{\underline{i}}\right.$ $-\Sigma M_{\underline{i}-2}$

$N$

Where $E x i$ is the variable main effect, $\Sigma M i+$ is the summation of the response value at high level; $\Sigma M i^{-}$is the summation of the response value at low level, and $N$ is the number of experiments. Statistical analysis of PBD is performed by using Design-Expert ${ }^{\circledR} 8$ software from Stat-Ease, Inc. Table (2). 
Table (1): Twelve trials Plackett-Burman experimental design with the response (chitinase activity).

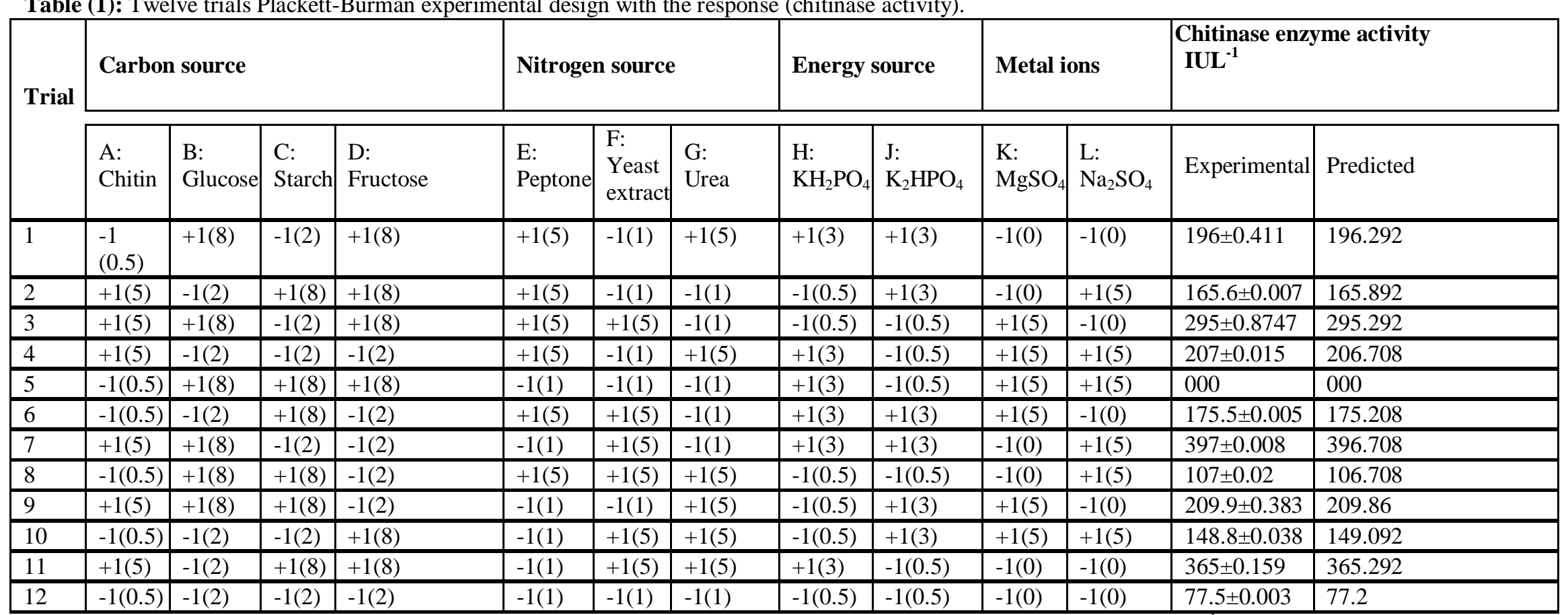

+1 and -1 represent the coded levels (high and low) of the independent variable. Real values (given in parentheses) are in gl ${ }^{-1}$ for carbon and nitrogen sources and energy sources. But in $\mathrm{mM}$ for metal ions. Values of response are the mean of duplicate cultivation experiments \pm SD. 
Table (2): Statistical analysis of Plackett-Burman design.

\begin{tabular}{|c|c|c|c|c|c|}
\hline Source & $\begin{array}{c}\text { Sum of } \\
\text { Squares }\end{array}$ & df & $\begin{array}{c}\text { Mean } \\
\text { Square }\end{array}$ & F-value & $\begin{array}{l}\text { P-value } \\
\text { Prob>F }\end{array}$ \\
\hline Model & $1.430 \mathrm{E}+005$ & 10 & 14302.27 & 14010.39 & 0.0066significant \\
\hline A-Chitin & 72805.34 & 1 & 72805.34 & 71319.52 & 0.0024 \\
\hline B-Glucose & 357.52 & 1 & 357.52 & 350.22 & 0.0340 \\
\hline C-Starch & 7415.24 & 1 & 7415.24 & 7263.91 & 0.0075 \\
\hline E-Peptone & 226.20 & 1 & 226.20 & 221.58 & 0.0427 \\
\hline F-Yeast extract & 33316.94 & 1 & 33316.94 & 32637.00 & 0.0035 \\
\hline G-Urea & 1262.80 & 1 & 1262.80 & 1237.03 & 0.0181 \\
\hline $\mathrm{H}-\mathrm{KH}_{2} \mathrm{PO}_{4}$ & 9447.24 & 1 & 9447.24 & 9254.44 & 0.0066 \\
\hline $\mathrm{J}_{-\mathrm{K}_{2}} \mathrm{HPO}_{4}$ & 4852.14 & 1 & 4852.14 & 4753.12 & 0.0092 \\
\hline K-MgSo 4 & 6160.80 & 1 & 6160.80 & 6035.07 & 0.0082 \\
\hline $\mathrm{L}-\mathrm{Na}_{2} \mathrm{SO}_{4}$ & 7178.52 & 1 & 7178.52 & 7032.02 & 0.0076 \\
\hline Residual & 1.02 & 1 & 1.02 & & \\
\hline Cor Total & $1.430 \mathrm{E}+005$ & 11 & & & \\
\hline
\end{tabular}

Std. Dev.=1.01, R-Squared =1.0000, Mean=195.36, Adj R-Squared=0.9999, C.V. \%=0.52, Pred R-Squared=0.9990, PRESS=147.00,

Adeq Precision=409.797. 
Optimization of medium with the Response Surface Methodology

Chitin, yeast extract and potassium di-hydrogen phosphate were identified as the key factors that influenced chitinase production from the above experiment, and their suitable concentration ranges were also preliminarily determined. Consequently, response surface methodology of central composite design (CCD) used for statistical optimization of B.diminuta KT277492 chitinase enzyme. ${ }^{25}, 26$. The 3-factor-5-level central composite design (CCD) with twenty experiments were carried out to determine the optimal concentration of chitin (A), yeast extract (B) and potassium di-hydrogen phosphate (C) and to develop a mathematical correlation between the three important variables and chitinase activity (Y). All three variables were investigated at low level (-1), zero level (0) and high level (+1), respectively, with $\alpha=1.682$. Codes and actual values of variables and matrix of CCD along with chitinase activity of each trial are shown in Table (3). The behavior of the system was explained by the following quadratic model equation.

$\mathrm{Y}$ (activity) $=\beta 0+\beta 1 \mathrm{~A}+\beta 2 \mathrm{~B}+\beta 3 \mathrm{C}+\beta 11 \mathrm{~A} 2+$ $\beta 22 \mathrm{~B} 2+\beta 33 \mathrm{C} 2+\beta 12 \mathrm{AB}+\beta 13 \mathrm{AC}+\beta 23 \mathrm{BC}$

where $Y$ (activity) was the predicted production of chitinase (IUL ${ }^{-1}$ ), $\beta 0$ intercept, $\beta 1, \beta 2$ and $\beta 3$ linear coefficients, $\beta 11, \quad \beta 22$ and $\beta 33$ quadratic coefficients and $\beta 12, \beta 13$ and $\beta 23$ interactive coefficients. $\mathrm{A}, \mathrm{B}$ and $\mathrm{C}$ were the independent variables corresponding to the concentration of chitin, yeast extract and potassium di-hydrogen phosphate, respectively. Statistical analysis of the model was performed to evaluate the analysis of variance (ANOVA) Table (4) and the quadratic models were represented as contour plots (3D) using Design-Expert ${ }^{\circledR} 8$ software from Stat-Ease, Inc. ${ }^{27}$. All experiments were carried out in duplicate and the averages of chitinase activity were taken as response.

\section{Partial purification of chitinase enzyme}

Fractional precipitation of chitinase with acetone take place. the precipitant was added to the cold culture filtrate in ice-salt bath until the required concentration was achieved. After isolating the precipitated fraction by centrifugation in a refrigerated centrifuge, the supernatant was subjected to further precipitation and the process was repeated. The enzyme fractions obtained (25,
50 and $75 \%$ acetone) were dried at room temperature and assayed for chitinase activity ${ }^{28}$.

\section{In-vitro estimation of B.diminuta KT277492 chitinase antifungal activities}

B.diminuta KT277492 chitinase enzyme was screened in-vitro against two pathogenic fungi by the agar diffusion technique in Petri dishes according to ${ }^{28,29}$. The root rot pathogenic fungal isolates (Fusarium solani NRC15 and Alternaria alternata NRC43) were obtained from the culture collection of the Department of Chemistry of Natural and Microbial Products, National Research Center, Cairo, Egypt. The microorganisms were passaged at least twice to ensure purity and viability. About $200 \mu \mathrm{l}$ of the partial purified enzyme was applied on each well (10 $\mathrm{mm}$ in diameter) made in the solidified inoculated potato dextrose agar plates. The plates incubated for $72 \mathrm{~h}$ at $28{ }^{\circ} \mathrm{C}$. The antifungal effect was evaluated by measuring the inhibition zone diameter (IZD) around wells of the enzyme in $(\mathrm{mm})$ at three different points and the average values are reported as Mean \pm SD using MS Excel.

\section{RESULTS}

\section{Chitinase enzyme production}

Qualitative test of colloidal chitin agar plates showed the ability of $B$. diminuta KT277492 to produce chitinase enzyme, which hydrolyzed chitin forming clear zone around the bacterial colony as shown in Fig. (1). Results also demonstrated the ability of the novel isolate to produce chitinase enzyme (95 $\left.\mathrm{IUL}^{-1}\right)$ in nutrient broth medium supplemented with $0.1 \%$ chitin better than the other bacterial isolates as mentioned in the previous study. Therefore, $B$. diminuta KT277492 was selected as the best bacterial isolate for further optimization and improvement for chitinase enzyme production ${ }^{8}$. 


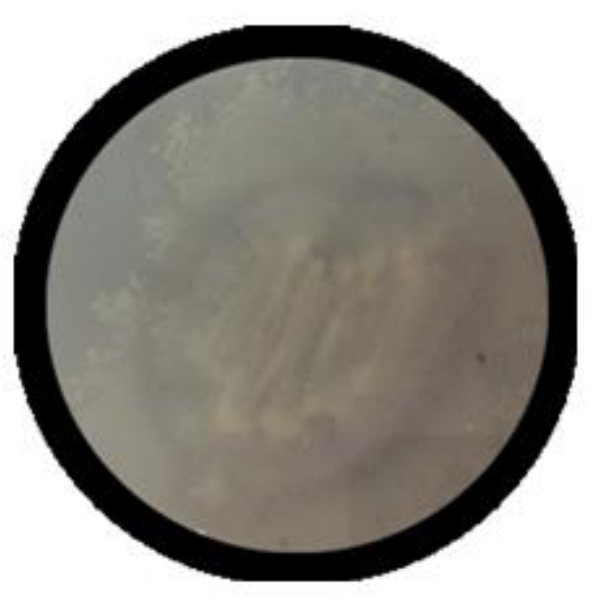

Fig. (1): Photo of colloidal chitin agar plate showing clear hydrolysis zone around the B.diminuta KT277492 indicting chitinase production.

\section{Optimization of B.diminuta KT277492 chitinase production}

Sequential optimization approaches were applied in the present part of the study. The first approach deals with the determination of the optimum incubation period, by one-variable-at-a-time method. The second approach deals with screening for nutritional factors affecting the selected bacterial isolate for chitinase production. The third approach is to optimize the factors that control the enzyme production process.

\section{Determination of the optimum incubation period}

One variable-at-a-time method is used to determine the optimum incubation period for chitinase production. Results indicated that at different incubation periods $(48,72,96,120,144$ and $168 \mathrm{~h})$ the activity was $(59.89,102.7,27,22$, 00.00 and $00.00 \mathrm{IUL}^{-1}$, resp.). The incubation period for $72 \mathrm{~h}$ was the most favorable for maximum chitinase production.

\section{Evaluation of the factors affecting chitinase production}

Eleven different medium constituents (variables) were chosen to perform the optimization process. The averages of chitinase activity of the different trials (experimental) together with the predicted activity are shown in Table (1). The data showed wide variation from 0 to $397 \pm 0.008 \mathrm{IUL}^{-1}$ of chitinase activity. This variation reflects the importance of medium optimization to attain c)higher productivity. The main effects of the examined variables on the enzyme activity were calculated and presented graphically in Fig. (2). Chitin, yeast extract, $\mathrm{KH}_{2} \mathrm{PO}_{4}$ showed the higher positive effect on chitinase activity followed by $\mathrm{K}_{2} \mathrm{HPO}_{4}$, urea and glucose, respectively. On the other hand, starch, fructose, peptone, $\mathrm{MgSO}_{4}$ and $\mathrm{Na}_{2} \mathrm{SO}_{4}$ were contributed negatively. Overall, the percentage contribution of the significant variables indicated that $50.90 \%$ was for initial chitin, $23.29 \%$ for yeast extract and $6.61 \%$ for $\mathrm{KH}_{2} \mathrm{PO}_{4}$, the remaining $19.2 \%$ for the other variables (Fig. 3). The first order model equation developed by $P B$ design showed the dependence of $B$. diminuta chitinase production on the medium constituent: $\mathrm{Y}$ $\left(\right.$ chitinase activity $\left.\mathrm{IUL}^{-1}\right)=+24.26157+34.61852 *$ chitin $+1.81944 *$ glucose $-8.28611 *$ starch $2.17083 *$ peptone $+26.34583 *$ yeast extract $+5.12917 *$ Urea $+22.44667 * \mathrm{KH}_{2} \mathrm{PO}_{4}$ $+16.08667 * \mathrm{~K}_{2} \mathrm{HPO}_{4}-9.06333 * \mathrm{MgSO}_{4}-9.78333 *$ $\mathrm{Na}_{2} \mathrm{SO}_{4}$

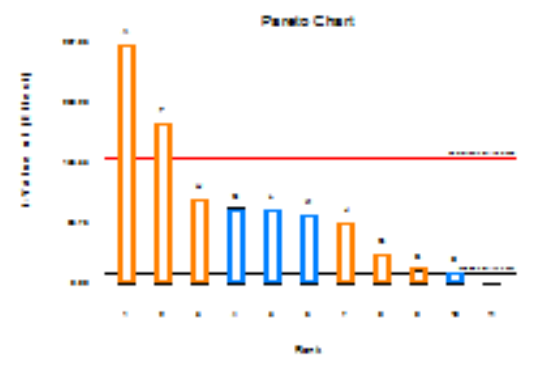

Fig. (2): Pareto chart of eleven-factor standard effects on chitinase production.
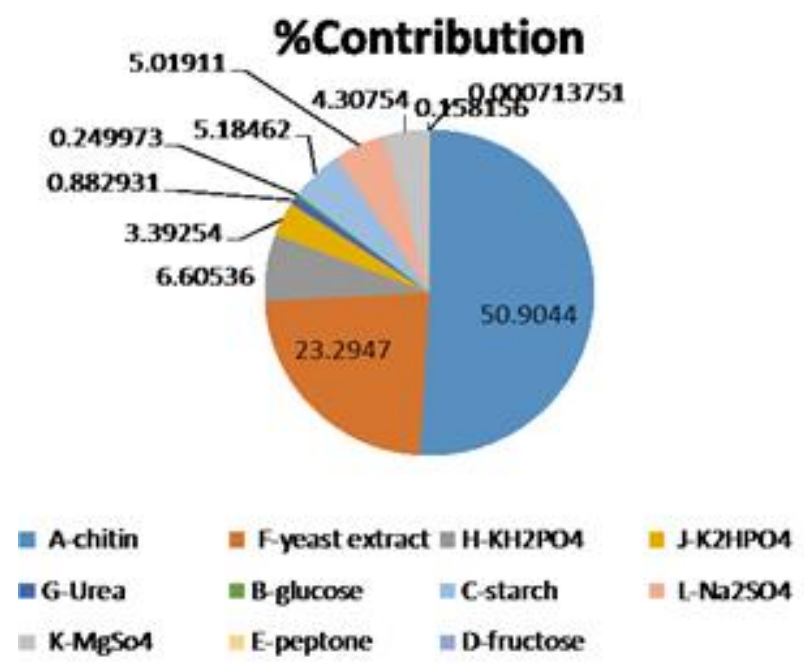

Fig. (3): The percentage contribution of the nutrient components.

Statistical analysis of the responses is represented in Table (2) The Model $F$ value of 14010.39 implies that the model is significant. Values of 
"Prob $>F$ " less than 0.0500 indicate that model terms are significant. In this case A, B, C, E, F, G, $\mathrm{H}, \mathrm{J}, \mathrm{K}, \mathrm{L}$ are significant model terms. In addition, the predicted $R^{2}$ was found to be 0.9990 , which is in reasonable agreement with the $R^{2}$ of 1.000 and adjusted $R^{2}$ of 0.9999 . This revealed that there is good agreement between the experimental and the theoretical values predicted by the model. The obtained results showed that varying of the chitin of the medium between $0.5-5 \mathrm{gl}^{-1}$ had high effect on chitinase production by $B$. diminuta. Maximal enzyme activities were obtained only when the chitin contribution in the culture medium was $5 \mathrm{gl}^{-}$ 1. According to these results, a medium of the following composition is expected to be near optimum $\left(\mathrm{gl}^{-1}\right)$ : chitin 5 , yeast extract $5, \mathrm{~K}_{2} \mathrm{HPO}_{4} 3$. The enzyme activity measurement on this medium was $397 \pm 0.008 \mathrm{IUL}^{-1}$. This result presented about 4.18-fold increase in the enzyme activity, when compared to the results obtained in basal production medium $\left(95 \mathrm{IUL}^{-1}\right)$. Variables with less significant effect were not included in the next optimization experiment but instead were used in all trials at their $(-1)$ level and $(+1)$ level, for the negatively contributing variables and the positively contributing variables, respectively.

\section{Optimization of the culture conditions by response surface design}

Effect of chitin, yeast extract and $\mathrm{KH}_{2} \mathrm{PO}_{4}$ concentrations on chitinase production were studied by response surface design. The individual and interactive effects of these media components were studied by carrying out the chitinase assay run at different randomly selected level as shown in Table (3). The results of experiments performed in this section showed that the maximum average yield of chitinase was $832.87 \pm 0.282 \mathrm{IUL}^{-1}$, which obtained under the following optimum conditions of the media $\left(\mathrm{gl}^{-1}\right)$ : chitin 8 , yeast extract 6, $\mathrm{KH}_{2} \mathrm{PO}_{4} 3$, glucose 8, urea 1 and $\mathrm{K}_{2} \mathrm{HPO}_{4} 3$. This result presented about 8.767 -fold increase in the enzyme activity, when compared to $\left(95 \mathrm{IUL}^{-1}\right)$, the results obtained in the first basal production medium, without any optimization. And about 2.0979-fold increase when compared with the maximum production yield from placketteBurman. This reflects the necessity and value of optimization process. The second-order regression equation provided the levels of chitinase activity can be presented in terms of Actual Factors: (Chitinase activity) $=-190.18212+139.66876^{*}$ Chitin $+213.58995^{*}$ yeast extract-58.60884*
$\mathrm{KH} 2 \mathrm{PO} 4+4.47329 *$ Chitin * yeast extract $+1.74450 *$ Chitin * KH2PO4 +11.61675* yeast extract-58.60884* KH2PO4 +4.47329* Chitin * yeast extract $+1.74450 *$ Chitin * KH2PO4 $+11.61675 *$ yeast extract * KH2PO4 -10.92271* Chitin $^{2}-28.87481 *$ yeast extract $^{2}++8.08712^{*}$ $\mathrm{KH}_{2} \mathrm{PO}^{2}$.

Analysis of variance (ANOVA) for the Quadratic model was shown in Table (4). Value of "Model Prob $>$ F" less than 0.0050 implied that the model was high significant. In this case $\mathrm{A}, \mathrm{B}, \mathrm{C}, \mathrm{AB}, \mathrm{AC}$, $\mathrm{BC}, \mathrm{A}^{2}, \mathrm{~B}^{2}, \mathrm{C}^{2}$ are significant model terms. The $\mathrm{R}^{2}$ coefficient obtained, of 1.0000 , suggests that it is a reliable model and the "Pred R-Squared" of 1.0000 is in reasonable agreement with the "Adj RSquared" of 1.0000. Three dimensional (3D) response surface plots of chitinase production based on the final model are depicted in Fig. (4) which were generated in pair-wise combination of the three factors while keeping the other one at its optimum level.

The validation was carried out under the optimum conditions of the media and the experimental chitinase production of $832.87 \pm 0.282 \mathrm{IUL}^{-1}$ was obtained which is closer to the predicted chitinase production of $832.821 \mathrm{IUL}^{-1}$; this result indicated the validity and the effectiveness of the proposed model.

a)

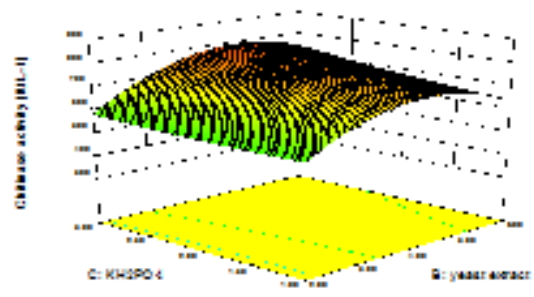

b)

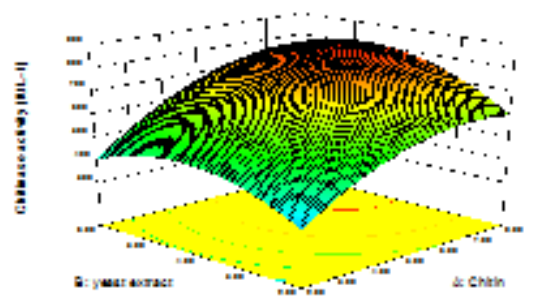


c)

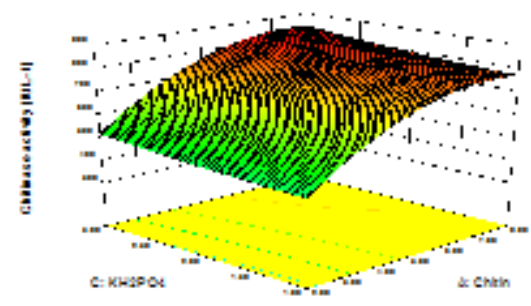

Fig. (4): Three dimensional response surface plot for the effect of (a) chitin and yeast extract, (b) chitin and $\mathrm{KH} 2 \mathrm{PO} 4$, (c) yeast extract and $\mathrm{KH} 2 \mathrm{PO} 4$

In-vitro antifungal activity of $B$. diminuta KT277492 chitinase enzyme

The antifungal properties of the chitinase enzyme partially purified from $B$. diminuta KT277492 in a petri medium against pathogenic fungi $F$. solani, and A. alternata are shown in Fig. (5). Results indicated that the enzyme has good antifungal effect against all pathogenic tested fungi causes rot to roots of plants but with different degrees. The tested pathogenic fungi can be arranged according to their degree of susceptibility for $B$. diminuta KT277492 chitinase enzyme as the following order A. alternata $>F$. solani, with zones of inhibition $31 \pm 0.25$ and $25 \pm 0.91 \mathrm{~mm}$, respectively.
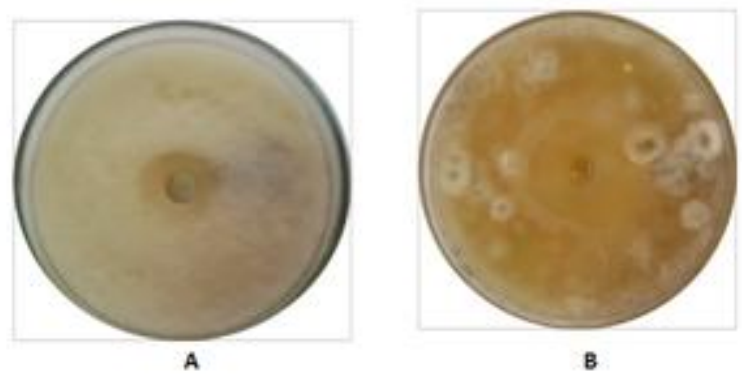

Fig. (5): The inhibition effect of partially purified chitinase enzyme from $B$. diminuta KT277492on $F$. solani (A) and A. alternata (B).

\section{DISCUSSION}

Chitin is usually thought as a kind of renewable polysaccharides and organic nitrogenous substance that only second respectively to cellulose and protein in abundance $\left[{ }^{1}\right]$. Several studies stated that chitin derivatives are of interest to people due to their diverse important applications. Therefore, isolating novel chitinase producing microorganisms and production optimization for high productivity are of great importance to the industry. In this context, a novel bacterial isolate
B. diminuta KT277492 with strong chitinolytic activity was studied for statistical optimization of chitinase production.

In this study, the Plackett-Burman design was used to determine the most important factors influencing $B$. diminuta KT277492 chitinase production. There are many reports describing the use of this method in medium optimization with several microorganisms including pseudomonas, paenibacillus ${ }^{13,}{ }^{30}$, Alcaligenes xylosoxydans ${ }^{26}$, Pantoea dispersa ${ }^{31}$, Streptomyces ${ }^{32}$, Azadirachta indica ${ }^{33}$, and Bacillus circulans ${ }^{34}$ Based on Plackett-Burman design results it was found that among eleven tested components, chitin, yeast extract and $\mathrm{KH}_{2} \mathrm{PO}_{4}$ exhibit statistically significant effect on chitinase enzyme production. These results agree with several studies that showed chitin is a major inducer in chitinase production by many bacteria such Stenotrophomonas maltophilia ${ }^{35}$, paenibacillus ${ }^{13,30}$ and Bacillus pumilus ${ }^{13}$. 
Table (3): Chitinase activity from the expermental design for the Response Surface Quadratic Model (RSM).

\begin{tabular}{|c|c|c|c|c|c|c|c|c|}
\hline \multirow{3}{*}{$\begin{array}{l}\text { Trial } \\
\text { number }\end{array}$} & \multicolumn{6}{|c|}{ Factor levels } & \multirow{2}{*}{\multicolumn{2}{|c|}{$\begin{array}{l}\text { Chitinase activity } \\
\text { IUL }^{-1}\end{array}$}} \\
\hline & \multicolumn{2}{|c|}{$\begin{array}{l}\text { Chitin } \\
\left(\mathrm{A}, \mathrm{gl}^{-1}\right)\end{array}$} & \multicolumn{2}{|c|}{$\begin{array}{l}\text { Yeast extract } \\
\left(\mathrm{B}, \mathrm{gl}^{-1}\right)\end{array}$} & \multicolumn{2}{|c|}{$\begin{array}{l}\mathrm{KH}_{2} \mathbf{P O}_{4} \\
\left(\mathrm{C}, \mathrm{gl}^{-1}\right)\end{array}$} & & \\
\hline & Coded & actual & coded & actual & coded & actual & Actual & Predicted \\
\hline 1 & -1 & 2.00 & -1 & 2.00 & +1 & 3.00 & $352.295 \pm 0.022$ & 352.188 \\
\hline 2 & 0 & 5.00 & -1.682 & 0.64 & 0 & 2.00 & $320.87 \pm 0.018$ & 320.899 \\
\hline 3 & 0 & 5.00 & +1.682 & 7.36 & 0 & 2.00 & $510.65 \pm 0.024$ & 510.547 \\
\hline 4 & -1.682 & 0.10 & 0 & 4.00 & 0 & 2.00 & $226.235 \pm 0.03$ & 226.200 \\
\hline 5 & -1 & 2.00 & +1 & 6.00 & -1 & 1.00 & $363.76 \pm 0.008$ & 363.883 \\
\hline 6 & 0 & 5.00 & 0 & 4.00 & 0 & 2.00 & $742.432 \pm 0.881$ & 742.714 \\
\hline 7 & 0 & 5.00 & 0 & 4.00 & 0 & 2.00 & $742.432 \pm 0.141$ & 742.714 \\
\hline 8 & 0 & 5.00 & 0 & 4,00 & 0 & 2.00 & $742.432 \pm 0.016$ & 742.714 \\
\hline 9 & +1 & 8.00 & -1 & 2.00 & +1 & 3.00 & $619.98 \pm 0.004$ & 619.919 \\
\hline 10 & 0 & 5.00 & 0 & 4.00 & 0 & 2.00 & $742.432 \pm 0.130$ & 742.714 \\
\hline 11 & 0 & 5.00 & 0 & 4.00 & -1.682 & 0.32 & $716.87 \pm 0.025$ & 716.625 \\
\hline 13 & 0 & 5.00 & 0 & 4.00 & +1.682 & 3.68 & $813.76 \pm 0.317$ & 813.391 \\
\hline 14 & +1 & 8.00 & -1 & 2.00 & -1 & 1.00 & $597.98 \pm 0.014$ & 597.051 \\
\hline 15 & +1 & 8.00 & +1 & 6.00 & +1 & 3.00 & $832.87 \pm 0.282$ & 832.821 \\
\hline 16 & +1 & 8.00 & +1 & 6.00 & -1 & 1.00 & $717.87 \pm 0.155$ & 717.677 \\
\hline 17 & 0 & 5.00 & 0 & 4.00 & 0 & 2.00 & $742.432 \pm 0.287$ & 742.714 \\
\hline 18 & 0 & 5.00 & 0 & 4.00 & 0 & 2.00 & $742.432 \pm 0.692$ & 742.714 \\
\hline 19 & +1.682 & 10.05 & 0 & 4.00 & 0 & 2.00 & $725.88 \pm 0.127$ & 725.839 \\
\hline 20 & -1 & 2.00 & -1 & 2.00 & -1 & 1.00 & $351.163 \pm 0.237$ & 351.264 \\
\hline
\end{tabular}


Table (4): Analysis of variance (ANOVA) for response surface quadratic model.

\begin{tabular}{|c|c|c|c|c|c|}
\hline Source & $\begin{array}{l}\text { Sum of } \\
\text { Squares }\end{array}$ & $\mathbf{d f}$ & $\begin{array}{l}\text { Mean } \\
\text { Square }\end{array}$ & F-value & $\begin{array}{l}\text { P-value } \\
\text { Prob>F }\end{array}$ \\
\hline Model & $6.902 \mathrm{E}+005$ & 9 & 76684.97 & $4.623 \mathrm{E}+006$ & $<0.0001$ significant \\
\hline A-Chitin & $3.260 \mathrm{E}+005$ & 1 & $3.260 \mathrm{E}+005$ & $1.965 \mathrm{E}+007$ & $<0.0001$ \\
\hline B-yeast extract & 43415.52 & 1 & 43415.52 & $2.618 \mathrm{E}+006$ & $<0.0001$ \\
\hline C-KH2PO4 & 11429.35 & 1 & 11429.35 & $6.891 \mathrm{E}+005$ & $<0.0001$ \\
\hline AB & 5762.98 & 1 & 5762.98 & $3.475 \mathrm{E}+005$ & $<0.0001$ \\
\hline $\mathbf{A C}$ & 219.12 & 1 & 219.12 & 13210.68 & $<0.0001$ \\
\hline BC & 4318.36 & 1 & 4318.36 & $2.604 \mathrm{E}+005$ & $<0.0001$ \\
\hline $\mathbf{A}^{2}$ & $1.332 \mathrm{E}+005$ & 1 & $1.332 \mathrm{E}+005$ & $8.028 \mathrm{E}+006$ & $<0.0001$ \\
\hline $\mathbf{B}^{2}$ & $1.925 \mathrm{E}+005$ & 1 & $1.925 \mathrm{E}+005$ & $1.160 \mathrm{E}+007$ & $<0.0001$ \\
\hline $\mathbf{C}^{2}$ & 943.64 & 1 & 943.64 & 56892.90 & $<0.0001$ \\
\hline Residual & 0.17 & 10 & 0.017 & & \\
\hline Lack of Fit & 0.17 & 5 & 0.033 & & \\
\hline Pure Error & 0.000 & 5 & 0.000 & & \\
\hline Cor Total & $6.902 \mathrm{E}+005$ & 19 & & & \\
\hline
\end{tabular}

R-Squared $=1.0000$, Adj R-Squared $=1.0000$, Pred R-Squared $=1.0000$, Adeq Precision $=6660.665$, Mean $=603.13$, umulative variance $($ C.V. $\%)=0.021$, PRESS $=$ 1.27 , Std. Dev. $=0.13$. 
It has been suggested that for most microorganisms the optimum chitin concentration for chitinase induction is in the range of $10-20 \mathrm{gl}^{-1}{ }^{25}$. In our investigation, we found that the optimum chitin concentration for chitinase production by $B$. diminuta KT277492 is 8 $\mathrm{gl}^{-1}$, which is considerably lower than the range given above. On the other hand ${ }^{13}$ demonstrated that the optimum chitin concentration for chitinase production by Bacillus pumilus is $4.76 \mathrm{gl}^{-1}$, which is considerably lower than the range we demonstrated.

The study of effect of additional nitrogen sources on chitinase production demonstrated that yeast extract as compared to urea and peptone, was found to have positive effect on chitinase production. According to Nawani and Kapadnis ${ }^{17}$, this may be due to the presence of chitin or growth factors in yeast extract. On the contradiction some other nitrogen sources including peptone and urea are reported to enhance chitinase production ${ }^{36}$ indicating that other mechanisms may be involved. The production of chitinolytic enzymes is also affected by minerals; we examined the effect of $\mathrm{KH}_{2} \mathrm{PO}_{4}, \mathrm{~K}_{2} \mathrm{HPO}_{4}, \mathrm{MgSO}_{4}$ and

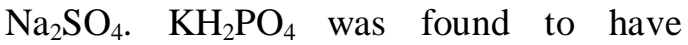
significant effect, while experiments showed that $\mathrm{K}_{2} \mathrm{HPO}_{4}, \mathrm{MgSO}_{4}$ and $\mathrm{Na}_{2} \mathrm{SO}_{4}$ had negative effect. ${ }^{35}$ work showed that $\mathrm{MgSO}_{4} \cdot 7 \mathrm{H}_{2} \mathrm{O}$ and $\mathrm{KH}_{2} \mathrm{PO}_{4}$ exerts positive effects on chitinase secretion in the presence of chitin. The maximum chitinase production was $832.87 \mathrm{IUL}^{-1}$. While Khan et al ${ }^{35}$ found that, maximum chitinase production from Stenotrphomonas maltophilia was $110 \mathrm{IUL}^{-1}$ using medium containing $4.94 \mathrm{gl}^{-1}$ chitin, $5.56 \mathrm{gl}^{-1}$ maltose, $0.62 \mathrm{gl}^{-1}$ yeast extract, $1.33 \mathrm{gl}^{-1} \mathrm{KH}_{2} \mathrm{PO}_{4}$, and $0.65 \mathrm{gl}^{-1} \mathrm{MgSO}_{4} \cdot 7 \mathrm{H}_{2} \mathrm{O}$. The chitinase producers appear potential candidates of biological control of pathogenic fungi. Several bacterial species are being reported as biofungicide. One of such bacteria was Bacillus subtilis TV-125 showed antifungal activity against Fusarium culmorum which is a pathogenic fungus that cause decomposition of roots of vegetables ${ }^{37}$. These results agree with our findings where the partially purified $B$. diminuta KT277492 chitinase enzyme showed good antifungal activity against pathogenic $F$. solani, and A. alternata. According to our findings, chitinase enzyme produced from the novel isolate $B$. diminuta KT277492 is expected to be used in the agriculture against fungal infections as biocontrol agent.

\section{CONCLUSIONS}

The evaluation of medium components for B. diminuta KT277492 chitinase production was done using the Plackett- Burman statistical method. Out of eleven components chitin, yeast extract and $\mathrm{KH}_{2} \mathrm{PO}_{4}$ were found to be the most significant variables and further optimization using response surface optimization technique. The enzyme production increased from 95 to 832.87 $\mathrm{IUL}^{-1}$ and this is presented about 8.767 -fold increase. Partially purified chitinase enzyme obtained from $B$. diminuta KT277492 showed good inhibitory effects against two pathogenic fungi.

\section{REFERENCES}

1- Hao Z, Yujie C, Xiangru L, Xiaoli Z, Zhiyou F, Dabing, Z. Optimization of nutrition factors on chitinase production from a newly isolated Chitiolyticbacter meiyuanensis. Braz. J. Microbiol. 2011; 3:177-186.

2- Chang SC, Wang JT, Vandamme P, Hwang JH, Chang PS. Adefensive roles for chitinases. In: Jolle's, Muzzarelli, R.A.A. (Eds.). 2004; 72: 1057-1083.

3- Graham LS, Sticklen MB. Plant chitinases of Serratia marcescens, Can. J. Microbiol.1994; 15: 689-696.

4- Boman HG. Peptide antibiotics and their role in innate immunity. Annu. Rev. Immunol., (1995); 13: 61-92.

5- Patil RS, Ghormande V, Deshpande MV. Chitinolytic enzymes: an exploration. Enzyme Microb Technol. 2000; 26: 473-483.

6- Abdel-Aziz SM, Moharam ME, Hamed HA, Mouafi FE. Extracellular Metabolites Produced by a Novel Strain, Bacillus alvei NRC-14: 1. Some Properties of the Chitinolytic System. New York Science Journal. 2012; 5(1): 53- 62.

7- Sim T, Oh JCS. Spent brewery as substrate for the production of cellulase by Trichoderma reesei QM 94114. J Ind Microbiol. 1990; 5: 153-8.

8- Ashour WE, Hamed ER, El-Diwany AI, Swelim MA, Abd El Aty AA. Isolation and 
Characterization of Plant Growth-Promoting Rhizobacteria from Trigonella foenumgraecum $L$ Rhizosphere and Evaluation of their Potential Substances Produced. Res. J. Pharm., Biol. Chem. Sci.2016; 7(3):130-143.

9- Murao S, Kawada T, Itoh H, Oyama H, Shin T.Purification and characterization of a novel type of chitinase from Vibrio alginolyticus. Biosci Biotech Bioch. 1992; 56: 368369.

10- Mathur A, Anita R, Gunjan B, Shikha B. Isolation of Bacillus producing chitinase from soil: production and purification of chito oligosaccharides from chitin extracted from fresh water crustaceans and antimicrobial activity of chitinase. Resent Res. Sci. Technol. 2011; 3: 1-6.

11- Kamal K, Brian G. Biological control of plant pathogens. Plant Health Inst. Doi: 10. 1094/PHI. A. 1117.02. 2011.

12- Mendonsa ES, Vartak PH, Rao JU, Deshpande MV. An enzyme from Myrothecium verrucaria that degrades insect cuticles for biocontrol of Aedes aegypti mosquito. Biotechnol Lett.1996; 18: 373-376. doi: 10. 1007/BF00143454.

13- Tasharrofi N, Sina A, Mehdi F, Hossein R, Mohammad RK, Mohammad AF. Optimization of Chitinase Production by Bacillus pumilus Using Plackett-Burman Design and Response Surface Methodology. IRAN J PHARM RES. 2011; 10(4): 759768.

14- Lu Y, Mei L. Optimization of fermentation conditions for P450 BM-3monooxygenase production by hybrid design methodology. J. Zhejiang Univ. Sci. B. 2007; 8: 27-32.

15- Plackett RL, Burman JP. The design of optimum multifactorial experiments. Biometrica. 1944;33: 305-325.

16- Myers RH, Montgomery D. Response Surface Methodology: Process and Product Optimization Using Designed Experiments. 2002. Wiley, New York.

17- Nawani NN, Kapadnis BP. novel chitinolytic bacterium isolated from a freshwater pond for shrimp Optimization of chitinase production using statistics based experimental designs. Process biochem. 2005; 40: 651-660.

18- Souza M, Roberto IC, Milagres AMF. Solid-State fermentation for xylanase production by Thermoascus aurantiacus using response surface methodology. Appl Microbiol Biotechnol. 1999;52: 768-772.

19- Kuddus SM, Ahmad RIZ. Isolation of novel chitinolytic bacteria and production optimization of extracellular chitinase. $\mathrm{J}$ of genetic engen \& biote. 2013; 11:39-46.
20- Sudhakar P, Nagarajan P. Production of chitinase by solid state fermentation from Serratia marcescens. International Journal of Chem.Tech. Research. 2011; 3(2): 590598.

21- Miller GL. Use of dinitrosalicylic acid reagent for determination of reducing sugars. Anal Chem. 1959; 31: 426-8.

22- Ulhoa CJ, Peberdy JF. Regulation of chitinase synthesis in Serratia marcescens. J Gen Microbiol. 1991; 14: 2163-9.

23- Roberts A, Selitrenkoff N. Colloidal chitin preparations. J Gen Microbiol, 1985; 134: 169-76.

24- Shehata AN, Abd El Aty AA. Optimization of process parameters by statistical experimental designs for the production of naringinase enzyme by marine fungi. Hindawi Publishing Corporation International J of Chem.Engineering, Article ID 273523, 10 pages. 2014

25- Sandhya C, Adapa LK, Nampoothiri KM, Binod P, Szakacs G, Padney A. Extracellular chitinase production by Trichoderma harzianum in submerged fermentation. J. Basic Microbiol. 2004; 44: 49-58.

26- Vaidya RJ, Shah IM, Vyas PR, Chhatpar HS. Production of chitinase and its optimization from a novel isolate Alcaligenesxylosoxydans: Potential in antifungal biocontrol. W. J.Microbiol. Biotech. 2011; 17: 691-696.

27- Adinarayana K, Ellaiah P, Srinivasulu B, Bhavani R, Adinarayana G. Response surface methodological approach to optimize the nutritional parameters for neomycin production by Streptomyces marinensis under solid-state fermentation. Process Biochem. 2003; 38:1565-1572.

28- Shehata AN, Abd El Aty AA. Improved production and partial characterization of chitosanase from a newly isolated Chaetomium globosum KM651986 and its application for chitosan oligosaccharides. J of Chem.and Pharm. Research, 2015; 7: 727740.

29- Mostafa FA, Abd El Aty AA, Hamed ER, Eid

$\mathrm{BM}$, Ibrahim NA. Enzymatic, kinetic and antimicrobial studies on Aspergillus terreus culture filtrate and Allium cepa seeds extract and their potent applications. Bioca and Agricu Biotech.2016;5:116-122.

30- Singh AK, Mehta G, Chhatpar HS. Optimization of medium constituents for improved chitinase production by Paenibacillus sp. D1 using statistical approach. Applied micro. 2009; 49: 708714. 
31- Gohel V, Chaudhary T, Vyas P, Chhatpar HS. Statistical screening of medium components for the production of chitinase by the marine isolate Pantoea dispersa. Biochem. Eng. J. 2006; 28: 50-56.

32- HanY, Zhiyong L, Miao X, Zhang F. Statistical optimization of medium components to improve the chitinase activity of Streptomyces sp. Da11 associated with the South China Sea sponge Craniella australiensis. Process Biochem. 2008; 43: 1088-1093.

33- Prakash G, Srivastava K. Statistical media optimization for cell growth and azadirachtin production in Azadirachta indica A. Juss suspension cultures. Process Biochem. 2005; 40: 3795-3800.

34- Volken de Souza CF, Flores SH, Ayub MAZ. Optimization of medium composition for production of transglutaminase by Bacillus circulans BL32 using statistical experimental design. Process Biochem. 2006; 41: 1186-1192.

35- Khan MA, Rifat H, Mahboob A, Abdin,MZ, Saleem J. Optimization of culture media for enhanced chitinase production from a novel strain of stenotrophomonas maltophilia using response surface methodology. J. Microbiol. Biotechnol. 2010; 20(11): 15971602.

36- Akhir SM, Abd-Aziz S, Salleh MM, Rahman RAM. Optimisation of chitinase enzyme production from shrimp waste using Bacillus licheniformis TH-1 by Response Surface Methods. Biotech. 2009; 8:120-125.

37- Senol M, Nadaroglu H, Dikbas N, Kotan R. Purification of Chitinase enzymes from Bacillus subtilis bacteria TV-125, investigation of kinetic properties and antifungal activity against Fusarium culmorum. Ann. of Clinical Micro. and Antimic., 2014; 13: 35.

Received: January 15, 2016; Accepted: May11, 2016 